\title{
Postnatal insulin secretion and sensitivity after manipulation of fetal growth by embryo transfer in the horse
}

\author{
A J Forhead, J C Ousey, W R Allen ${ }^{\mathbf{1}}$ and A L Fowden \\ Department of Physiology, University of Cambridge, Downing Street, Cambridge, CB2 3EG, UK \\ ${ }^{1}$ Department of Clinical Veterinary Medicine, University of Cambridge, Cambridge, CB3 OES, UK \\ (Requests for offprints should be addressed to A L Fowden; Email: alf1000@cam.ac.uk)
}

\begin{abstract}
This study examined the effects of intrauterine growth on insulin secretion and resistance in newborn foals. Embryo transfer between small pony and large Thoroughbred mares was used to produce four groups of foals with different birth weights (pony in pony $n=7$; pony in Thoroughbred $n=7$; Thoroughbred in Thoroughbred $n=8$; Thoroughbred in pony $n=8)$. On day 2 after birth, glucose $(0.5 \mathrm{~g} / \mathrm{kg})$ was administered intravenously to the foal and blood samples were taken for $2 \mathrm{~h}$ to determine plasma glucose and insulin concentrations. On day 3, insulin sensitivity was assessed by giving insulin $(0 \cdot 75$ $\mathrm{U} / \mathrm{kg}$ i.v.) and measuring the decrement in plasma glucose in the foals. There were no significant differences in
\end{abstract}

insulin secretion, insulin sensitivity or glucose tolerance between the control and growth-retarded Thoroughbred foals. Overgrown pony foals delivered by Thoroughbred mares had higher basal insulin levels and greater $\beta$ cell responses to glucose than the other groups of foals. The relationship between plasma glucose and insulin was also significantly steeper in overgrown pony foals than in the other groups. Variations in intrauterine growth rate, therefore, affect postnatal insulin secretion in the horse. More specifically, it is overgrowth, not growth retardation in utero that alters equine $\beta$ cell function in the immediate neonatal period.

Journal of Endocrinology (2004) 181, 459-467

\section{Introduction}

Epidemiological studies in man have shown that both high and low birth weight are associated with an increased risk of glucose intolerance and non-insulin dependent Type 2 diabetes in adult life (Hales et al. 1991, Phillips et al. 1994b, Williams et al. 1999, Lindsay \& Bennett 2001). These associations have been linked to changes in nutrient provision to the fetus and have led to the hypothesis that adult metabolic diseases are programmed by nutritional conditions in utero (Hales \& Baker 1992, Hoet \& Hanson 1999, Aerts \& Van Assche 2003). More specifically, this hypothesis proposes that, when nutrients are either plentiful or scarce, there are metabolic and endocrine adaptations in the fetus which match the intrauterine growth rate to the nutrient supply, with beneficial effects for survival in the short term but which have detrimental effects on the secretion and effectiveness of insulin in the long term and increase susceptibility to metabolic disease in adult life (Hales et al. 1996, Hoet \& Hanson 1999, Aerts \& Van Assche 2003).

Prenatal programming of postnatal metabolic function has been investigated experimentally in a number of species, including rats, guinea pigs, pigs and sheep (Aerts \& Van Assche 1979, Holemans et al. 1997, Moss et al. 2001, Simmons et al. 2001, Poore \& Fowden 2002, Kind et al. 2003). In these studies, nutrient availability to the fetus was either increased by inducing maternal diabetes or reduced using a range of techniques including restriction of dietary intake, uterine blood flow and placental size (Aerts et al. 1990, Hales et al. 1996, Holemans et al. 1997, Hoet \& Hanson 1999, Simmons et al. 2001). These experiments all support the hypothesis that adult metabolic disease originates in utero and confirm that the pattern of fetal growth and development has consequences for glucose metabolism long after birth. Similarly, when fetal growth is altered spontaneously in man and other species during twin or multiple pregnancies, the resultant low birth weight is associated with perturbed glucose metabolism in later life (Poulsen et al. 1997, Poore \& Fowden 2002, Clarke et al. 2000). In rats, the postnatal abnormalities in glucose tolerance observed after both fetal micro- and macrosomia appear to be caused primarily by changes in pancreatic $\beta$ cell function and insulin secretion (Hoet \& Hanson 1999, Aerts \& Van Assche 2003) whereas in humans and pigs, the associations between birth weight and adult glucose intolerance are more closely related to insulin resistance than insulin deficiency (Phillips et al. 1994a, Plagemann et al. 1997, Ravelli et al. 1998, Poore \& Fowden 2002).

In species such as the pig and horse, in which placentation occurs over the entire uterine surface 
(Steven 1975), the placental supply of nutrients and oxygen to the fetus depends on the size of the uterus, which, in turn, is determined by the size of the mother. Experimental studies of embryo transfer or of breeding reciprocal crosses between small and large breeds of these species have shown that fetal growth is determined by the uterine capacity of the mother (Walton \& Hammonds 1938, Tischner 1987, Allen et al. 2002a). In the horse, manipulation of intrauterine growth by embryo transfer between small pony and large Thoroughbred mares leads to altered cardiovascular and endocrine function in the foals shortly after birth (Giussani et al. 2003). However, the extent to which postnatal glucose handling is affected by these embryo transfer techniques remains unknown. Hence, this study investigated the secretion of, and sensitivity to, insulin in newborn foals with different intrauterine growth rates caused by embryo transfer between pony and Thoroughbred mares.

\section{Materials and Methods}

\section{Establishment of pregnancy}

Within-breed insemination Mares from a pony $(\mathrm{P})$ herd and a Thoroughbred (TB) herd were artificially inseminated once during oestrus when ultrasound examination of their ovaries revealed a dominant follicle of $>35 \mathrm{~mm}$ in diameter (Allen et al. 2002a). Mares were inseminated with 5-10 $\mathrm{ml}$ fresh semen collected from a stallion of the same breed using an artificial vagina. The semen was diluted with an equal volume of skim milk glucose extender containing antibiotics. At the time of insemination, each mare was given an intravenous injection of human chorionic gonadotrophin (Chorulon; Intervet Laboratories, Milton Keynes, UK; 1500 I.U. for ponies and 3000 I.U. for Thoroughbreds) to induce ovulation, which was diagnosed by ultrasound and confirmed by measurement of plasma progesterone concentrations (Allen et al. 2002a). Pregnancy was diagnosed ultrasonically between 11 and 14 days after ovulation (Allen et al. 2002a).

Between-breed embryo transfer Other mares from the two herds were examined, treated and had blood samples taken as above but were divided arbitrarily into donor and recipient groups for embryo transfer. The donors were inseminated with semen from the stallion of the same breed while the recipient mares were not inseminated. On day 7 after ovulation (day 0 ) the uteri of the donor mares were flushed three times with embryo flushing medium. The infused fluid was recovered by gravity flow through an in-line embryo filter (Em-Com, Immuno Systems, Wisconsin, WI, USA) using the final $20 \mathrm{ml}$ fluid to search for the presence of an embryo. Recovered embryos were washed three times in fresh medium before being transfered non-surgically via the cervix into the uteri of recipient mares that had ovulated 1-3 days after the respective donors. Pregnancy in the recipient mares was diagnosed ultrasonographically 7-9 days after transfer and was monitored at frequent intervals thereafter until approximately day 60 .

These manipulations resulted in four experimental groups: pony fetuses carried by pony mares ( $\mathrm{P}$ in $\mathrm{P}, n=7)$, pony fetuses carried by Thoroughbred mares ( $\mathrm{P}$ in $\mathrm{TB}$, $n=7$ ), Thoroughbred fetuses carried by Thoroughbred mares (TB in TB, $n=8$ ) and Thoroughbred fetuses carried by pony mares (TB in $\mathrm{P}, n=8)$.

\section{Postnatal measurements and experimental procedures}

All births were supervised and occurred spontaneously at gestational ages ranging from 313 days to 348 days. Occasionally, manual assistance was given either during delivery and/or immediately thereafter to help the foal to stand and suck. A blood sample was taken by venipuncture from the jugular vein immediately after birth for the determination of packed cell volume (PCV) and the haemoglobin concentration. Within $30 \mathrm{~min}$ of delivery, all the foals were weighed and assessed for maturity using standard clinical criteria (Rossdale et al. 1984). The placenta was collected immediately after delivery and, after it was weighed and measured, random samples were fixed for determination of the percentage of chorion (Allen et al. 2002a). The total microscopic area of the placenta was calculated by multiplying the surface density of the microcotyledons (Sv) by the volume of the chorionic portion $(\mathrm{Vc})$ of each placenta. The surface density of the microcotyledons $(\mathrm{Sv})$ was measured stereologically on 10 randomly selected samples of the allantochorion. The volume of the chorion $(\mathrm{Vc})$ was determined by multiplying the volume of allantochorion $(\mathrm{Va})$ by the percentage of allantochorion that was just chorion $(\mathrm{Pc} / 100)$ (Allen et al. 2002a). The volume of allantochorion (Va) was obtained by fluid displacement at birth, while the chorionic percentage was estimated histologically from the 10 necropsy samples (Allen et al. 2002a). The total microscopic area of feto-maternal placental interface $(\mathrm{S})$ in $\mathrm{m}^{2}$ was calculated using the following formula: $\mathrm{S}=\mathrm{Sv} \times \mathrm{Vc}$ where $V_{c}=V_{a} \times P_{c} / 100$. The data on gestational length, foal birthweight and the morphometry of the placenta for the four groups of animals has been published previously (Allen et al. 2002a, Giussani et al. 2003).

On the day of birth (day 1), a long-term catheter (16 g, central venous catheter, Arrow Internatiuonal Inc., Reading, PA, USA ) with an extension tube (Tset; Mila International Inc., Florences, KY, USA) was inserted into a jugular vein of each foal. On day 2 , the foals were infused intravenously with glucose $(0.5 \mathrm{~g} / \mathrm{kg} \quad 50 \%$ dextrose, Arnolds, Harlescott, Shrewsbury, Shropshire, UK) over 5 min to assess glucose clearance and the pancreatic $\beta$ cell response to glucose. The catheter was flushed with $10-20 \mathrm{ml}$ saline $(0 \cdot 9 \% \mathrm{w} / \mathrm{v})$ immediately after glucose 
administration. Blood samples $(3 \mathrm{ml})$ were taken through the jugular catheter at -30 and 0 min (immediately before) and 5, 15, 30, 45, 60, 90 and $120 \mathrm{~min}$ after glucose administration for measurement of plasma glucose and insulin concentrations. An extra $1 \mathrm{ml}$ blood was collected at $0 \mathrm{~min}$ and added to a chilled EDTA tube containing a protease inhibitor (Trasylol, Bayer UK Ltd, Newbury, Berks, UK; 2000 Kallikrein inactivator units per $\mathrm{ml}$ blood) for glucagon analysis. On day 3, the insulin sensitivity of the foals was assessed by monitoring the fall in the plasma glucose concentration in response to a bolus administration of insulin $(0.75 \mathrm{U} / \mathrm{kg}$ i.v. Novo Acta rapid human insulin). Blood samples were taken at -30 and $0 \mathrm{~min}$ before and at 5 and $15 \mathrm{~min}$ after insulin administration for the measurement of plasma glucose. An extra $1 \mathrm{ml}$ blood was taken at $0 \mathrm{~min}$ and added to a chilled heparin tube containing reduced glutathione ( $4 \mathrm{nmol} /$ tube) and EGTA ( $5 \mathrm{nmol} /$ tube) for the measurement of catecholamine concentrations. The foals were muzzled to prevent suckling from $-30 \mathrm{~min}$ to the end of the sampling period in both experiments. All blood samples were centrifuged immediately at $3000 \mathrm{~g}$ and $4{ }^{\circ} \mathrm{C}$ for $5 \mathrm{~min}$ and the plasma was decanted and stored at $-20^{\circ} \mathrm{C}$.

All procedures were carried out under the UK Animals (Scientific Procedures) Act 1986.

\section{Biochemical analyses}

Plasma glucose concentrations were measured using a Yellow Springs glucose analyser (YSI 2300 Stat Plus, Yellow Springs, Ohio, USA). Plasma insulin and glucagon concentrations were determined by radioimmunoassay validated for use with equine plasma as described previously (Fowden et al. 1980, 1999). The minimum detectable quantity of insulin was $2 \cdot 0 \mu \mathrm{U} / \mathrm{ml}$ and the intra- and interassay coefficients of variation were $7 \cdot 5 \%$ and $11.5 \%$ respectively. The minimum detectable concentration of glucagon was $30 \mathrm{pg} / \mathrm{ml}$ and the intra- and interassay coefficients of variation were $6 \%$ and $8 \%$ respectively. Plasma catecholamine concentrations were determined using high performance liquid chromatography with electrochemical detection (Silver et al. 1987). Briefly, $250 \mu \mathrm{l}$ plasma were absorbed onto acid-washed alumina and $20 \mu \mathrm{l}$ aliquots of the $100 \mu \mathrm{l}$ perchloric acid elutes were injected onto the column. Dihydroxybenzylamine was added as the internal standard to each plasma sample and its concentration used to correct for recovery. The minimum detectable quantity of adrenaline and noradrenaline was $20 \mathrm{pg} / \mathrm{ml}$.

\section{Calculations and statistical analyses}

For each glucose tolerance test, the areas under the glucose and insulin response curves (AUC) were calculated by integrating the increment in plasma concentration after glucose administration (from 5 to $120 \mathrm{~min}$ ) above the mean pre-infusion baseline (30 and $0 \mathrm{~min}$ ). To calculate the glucose half time $\left(t^{1} / 2\right)$, an exponential (e) decay curve was fitted to the plasma glucose concentrations during the response $(5-120 \mathrm{~min})$. The $\mathrm{t}^{1 / 2}$ was calculated using the formula: $\mathrm{t}^{1 / 2}=0.69 \times \mathrm{b}^{-1}$ where glucose concentration= peak glucose concentration $\times \mathrm{e}^{-\mathrm{b}(\text { time })}+$ basal glucose concentration. The glucose decrement over the first $15 \mathrm{~min}$ after insulin administration was used to assess insulin sensitivity, as the counter regulatory response is minimal at this time (Forhead \& Dobson 1997). All results are expressed as means \pm S.E. Comparisons within and between groups were assessed using either one-way or two-way ANOVA with or without repeated measures followed by the Tukey post hoc tests, as appropriate. The slopes of the relationship between plasma insulin and glucose concentrations were analysed by linear regression and their statistical significance assessed using the method of Armitage and Berry 1994. When required, data were $\log$ transformed to normalise distribution.

\section{Results}

\section{Morphometry and pregnancy outcome}

The mean body weight and placental area of the foals at birth are shown in Table 1. The mean birth weight of the $\mathrm{TB}$ in TB foals was significantly higher than that of the $\mathrm{P}$ in $\mathrm{P}$ foals $(P<0 \cdot 01$, Table 1$)$. The mean birth weight of the $\mathrm{P}$ in $\mathrm{TB}$ foals was significantly higher than that of the $\mathrm{P}$ in $\mathrm{P}$ control animals and, conversely, the mean birth weight of the TB in $\mathrm{P}$ foals was significantly lower than that of the TB in TB foals $(P<0 \cdot 01$ both cases, Table 1$)$. Two-way ANOVA showed significant effects of both maternal $(P<0 \cdot 01)$ and fetal genomes $(P<0 \cdot 01)$ on foal birth weight, and greater birth weights were associated with a TB genome regardless of whether maternal or fetal in origin. The total placental area was highest in the TB in $\mathrm{TB}$ pregnancies and lowest in the $\mathrm{P}$ in $\mathrm{P}$ pregnancies with intermediate values in the other two groups (Table 1). Two-way ANOVA showed that both the maternal and fetal genomes were significant influences on total placental area $(P<0.002$ both cases).

All the mares delivered within the range of gestational ages considered full term for their breed (Rossdale 1976). The mean duration of gestation was longest in the TB in $\mathrm{TB}$ pregnancies and shortest in the $\mathrm{P}$ in $\mathrm{P}$ pregnancies with intermediate values in the other two groups (Table 1). Two-way ANOVA of the data showed significant effects of both the maternal $(P<0.029)$ and fetal $(P<0 \cdot 015)$ genome on the duration of pregnancy with a longer gestation with a TB genome irrespective of whether this was the mare or the foal. All foals were categorised as mature immediately after birth, whatever their gestational age at delivery. 
Table 1 Mean ( \pm S.E.) values of birth weight, placental area, gestational age packed cell volume (PCV), basal concentrations of blood haemoglobin $(\mathrm{Hb})$, plasma glucose, insulin and glucagon and the ratio of the plasma concentrations of insulin to glucose in the different groups of foals (Thoroughbred in Thoroughbred, TB in TB, $n=8$; Thoroughbred in pony, $\mathrm{TB}$ in $\mathrm{P}, n=8$; pony in pony, $\mathrm{P}$ in $\mathrm{P}, n=7$; pony in Thoroughbred, $\mathrm{P}$ in $\mathrm{TB}, n=7$ except for glucagon where $n=5$ in each group)

\begin{tabular}{|c|c|c|c|c|}
\hline & TB in TB & TB in $\mathbf{P}$ & $P$ in $P$ & $\mathbf{P}$ in TB \\
\hline Body weight $(\mathrm{kg})$ & $52 \cdot 7 \pm 2 \cdot 3^{a}$ & $33 \cdot 0 \pm 2 \cdot 4^{b}$ & $24 \cdot 0 \pm 1 \cdot 3^{c}$ & $37 \cdot 9 \pm 2 \cdot 2^{b}$ \\
\hline Placental area $\left(\mathrm{m}^{2}\right)$ & $42 \cdot 0 \pm 4 \cdot 5^{a}$ & $29 \cdot 4 \pm 2 \cdot 6^{b, c}$ & $19 \cdot 4 \pm 1 \cdot 5^{c}$ & $34 \cdot 2 \pm 2 \cdot 0^{\mathrm{a}, \mathrm{b}}$ \\
\hline Gestational age (days) & $338 \cdot 0 \pm 3 \cdot 0^{\mathrm{a}}$ & $332 \cdot 0 \pm 2 \cdot 8^{a, b}$ & $324 \cdot 6 \pm 3 \cdot 0^{b}$ & $331 \cdot 1 \pm 2 \cdot 7^{\mathrm{a}, \mathrm{b}}$ \\
\hline PVC (\%) & $44 \cdot 0 \pm 1 \cdot 1$ & $42 \cdot 7 \pm 1 \cdot 4$ & $44 \cdot 2 \pm 1 \cdot 3$ & $47 \cdot 2 \pm 2 \cdot 5$ \\
\hline $\mathrm{Hb}(\mathrm{g} / \mathrm{dl})$ & $14 \cdot 7$ & $14 \cdot 3 \pm 0 \cdot 4$ & $14 \cdot 6$ & $16 \cdot 0 \pm 0 \cdot 9$ \\
\hline Insulin $(\mu \mathrm{U} / \mathrm{ml})$ & $5 \cdot 1 \pm 0 \cdot 6^{\mathrm{a}}$ & $6 \cdot 6 \pm 1 \cdot 2^{\mathrm{a}}$ & $13 \cdot 9 \pm 4 \cdot 1^{\mathrm{a}, \mathrm{b}}$ & $31 \cdot 5 \pm 5 \cdot 5^{\mathrm{b}}$ \\
\hline Glucose (mmol) & $10 \cdot 89 \pm 1 \cdot 00$ & $12 \cdot 48 \pm 1 \cdot 49$ & $12 \cdot 90 \pm 0 \cdot 71$ & $13 \cdot 91 \pm 0 \cdot 68$ \\
\hline Ratio of insulin:glucose & $0 \cdot 49 \pm 0 \cdot 05^{a}$ & $0 \cdot 52 \pm 0 \cdot 07^{a}$ & $1 \cdot 06 \pm 0 \cdot 31^{\mathrm{a}, \mathrm{b}}$ & $2 \cdot 03 \pm 0 \cdot 38^{b}$ \\
\hline Glucagon (pg/ml) & $769 \pm 214$ & $1027 \pm 473$ & $852 \pm 125$ & $1499 \pm 455$ \\
\hline
\end{tabular}

${ }^{a-c}$ Values within rows with different superscripts are significantly different from each other (one-way ANOVA $P<0 \cdot 05)$. Two-way ANOVA of the data is presented only in the text.

\section{Basal metabolite and hormone concentrations}

There were no significant differences in the basal concentrations of plasma glucose between the four groups of foals (Table 1). However, basal concentrations of plasma insulin differed between the groups and were highest in the $\mathrm{P}$ in TB foals (Table 1). Two-way ANOVA showed that the fetal $(P<0 \cdot 01)$, but not the maternal $(P>0 \cdot 05)$, genome was a significant influence on the plasma insulin level, with higher insulin levels in $\mathrm{P}$ than TB foals irrespective of the maternal genome. There was also a significant interaction between the fetal and maternal genomes $(P<0 \cdot 01)$ in determining plasma insulin levels with higher insulin levels in $\mathrm{P}$ foals delivered by $\mathrm{TB}$ mares than in those carried by $\mathrm{P}$ mares. The ratio of basal insulin and glucose concentrations was also highest in the $\mathrm{P}$ in $\mathrm{TB}$ foals (Table 1). Two-way ANOVA of the data showed that the fetal and maternal genomes were both significant factors $(P<0 \cdot 001$, both cases $)$ in determining this ratio and that there was a significant interaction between the two genomes $(P<0 \cdot 02)$ with a greater ratio in $\mathrm{P}$ foals carried by $\mathrm{TB}$ mares than in those gestated by $\mathrm{P}$ mares.

There were no significant differences in the plasma concentrations of glucagon and adrenaline between the four groups of foals using either one-way (Tables 1 and 2) or two-way ANOVA $(P>0.05$ for both fetal and maternal genomes in all cases). Using two-way ANOVA, the fetal $(P<0.025)$ but not the maternal $(P>0.05)$ genome was a significant influence on the plasma noradrenaline concentration with higher concentrations in $\mathrm{P}$ than TB foals. No significant differences in the PCV or blood haemoglobin concentrations were observed between the four groups of foals using either one-way (Table 1) or two-way ANOVA $(P>0 \cdot 05$, all cases for both fetal and maternal genomes).

Table 2 Mean ( \pm S.E.) values of basal concentration of plasma adrenaline, noradrenaline and glucose and the mean change $(\triangle)$ in plasma glucose 5 and 15 min after insulin administration expressed in absolute values $(\mathrm{mmol} / \mathrm{l})$ and as a percentage of the basal value (\%) in the four groups of foals, (Thoroughbred in Thoroughbred, TB in TB, $n=6$; Thoroughbred in pony, TB in $\mathrm{P}, n=7$; pony in pony, $\mathrm{P}$ in $\mathrm{P}, n=7$; pony in Thoroughbred, $P$ in TB, $n=6$ )

\begin{tabular}{|c|c|c|c|c|}
\hline & TB in TB & $T B$ in $P$ & $\mathbf{P}$ in $\mathbf{P}$ & $P$ in $T B$ \\
\hline Adrenaline $(\mathrm{pg} / \mathrm{ml})$ & $227 \pm 92$ & $202 \pm 104$ & $107 \pm 43$ & $181 \pm 53$ \\
\hline Noradrenaline (pg/ml) & $258 \pm 59$ & $243 \pm 35$ & $422 \pm 87$ & $316 \pm 25$ \\
\hline Basal glucose $(\mathrm{mmol} / \mathrm{l})$ & $10.96 \pm 1.00$ & $9 \cdot 96 \pm 1 \cdot 00$ & $10 \cdot 70 \pm 0 \cdot 70$ & $11 \cdot 90 \pm 0 \cdot 50$ \\
\hline $\begin{array}{l}\Delta \underset{\mathrm{mmol} / \mathrm{l}}{\Delta} \\
\mathrm{m}\end{array}$ & $\begin{array}{l}-2 \cdot 22 \pm 0 \cdot 34 \\
-21 \cdot 3 \pm 3 \cdot 0\end{array}$ & $\begin{array}{l}-2 \cdot 93 \pm 0.40 \\
-31 \cdot 3 \pm 4.2\end{array}$ & $\begin{array}{l}-3 \cdot 11 \pm 0 \cdot 79 \\
-27 \cdot 4 \pm 6 \cdot 0\end{array}$ & $\begin{array}{l}-3 \cdot 21 \pm 0.58 \\
-26.9 \pm 4 \cdot 1\end{array}$ \\
\hline $\begin{array}{l}\Delta \text { Glucose }(15 \mathrm{~min}) \\
\mathrm{mmol} / \mathrm{l} \\
\%\end{array}$ & $\begin{array}{l}-7 \cdot 72 \pm 1 \cdot 05 \\
-70 \cdot 4 \pm 2 \cdot 1\end{array}$ & $\begin{array}{l}-7 \cdot 25 \pm 0 \cdot 50 \\
-73 \cdot 9 \pm 3 \cdot 4\end{array}$ & $\begin{array}{l}-6 \cdot 25 \pm 8 \cdot 6 \\
-57 \cdot 3 \pm 5 \cdot 5\end{array}$ & $\begin{array}{l}-7 \cdot 40 \pm 0 \cdot 69 \\
-62 \cdot 9 \pm 5 \cdot 3\end{array}$ \\
\hline
\end{tabular}



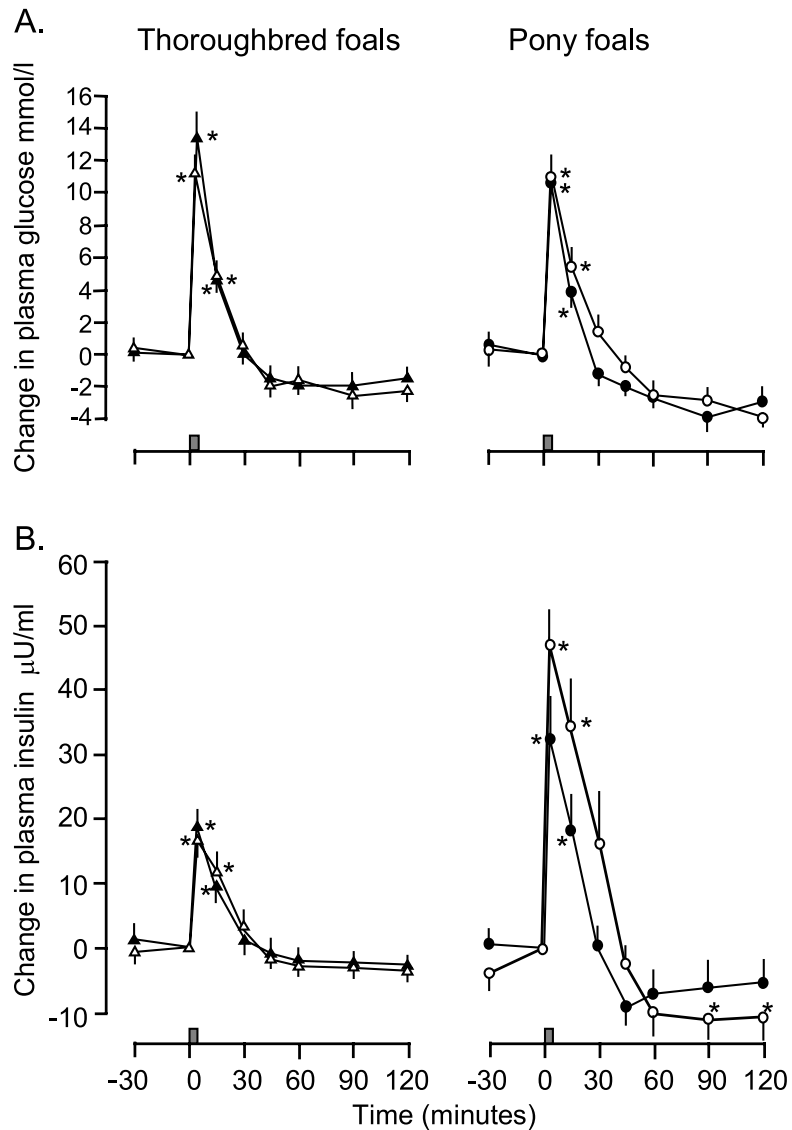

Figure 1 Mean ( \pm S.E.) changes in the plasma concentrations of (A) glucose and (B) insulin in response to glucose administration (grey box) in the four groups of foals $(\boldsymbol{\Lambda}$, Thoroughbred foals in Thoroughbred mothers (TB in TB), $n=8 ; \triangle$, Thoroughbred foals in pony mothers (TB in $\mathrm{P}$ ), $n=8$; $\bullet$, pony foals in pony mothers $(\mathrm{P}$ in $\mathrm{P}), n=7 ; \mathrm{O}$, pony foals in Thoroughbred mothers ( $\mathrm{P}$ in $\mathrm{TB}$ ), $n=7) .{ }^{*} P<0 \cdot 05$, significant change in concentration from the 0 min (pre-infusion) value (one-way ANOVA with repeated measures).

\section{Insulin secretion in response to exogenous glucose}

Administration of glucose evoked a rapid release of insulin with peak insulin concentrations at the end of the 5-min infusion of glucose in all four groups of foals (Fig. 1). The maximum increment in plasma insulin was significantly greater in $\mathrm{P}$ in TB foals $(+49 \cdot 5 \pm 6 \cdot 1 \mu \mathrm{U} / \mathrm{ml}, n=7)$ than in the other three groups of foals ( $\mathrm{P}$ in $\mathrm{P},+31 \cdot 5 \pm 7 \cdot 3 \mu \mathrm{U}$ / $\mathrm{ml}, n=7 ; \mathrm{TB}$ in $\mathrm{TB},+18.9 \pm 2 \cdot 1 \mu \mathrm{U} / \mathrm{ml}, n=8$; $\mathrm{TB}$ in $\mathrm{P},+16 \cdot 8 \pm 2 \cdot 0 \mu \mathrm{U} / \mathrm{ml}, n=8, P<0 \cdot 05$ all cases, one-way ANOVA). The insulin AUC was also greatest in the $\mathrm{P}$ in TB foals (Fig. 2A). Two-way ANOVA using fetal and maternal genomes as factors showed significant effects of the fetal, but not the maternal, genome on the maximum increment in plasma insulin (fetus $P<0.001$, mother $P>0.05$ ) and on the insulin AUC (fetus $P<0.003$, mother $P>0 \cdot 05$ ), with greater values in $\mathrm{P}$ than $\mathrm{TB}$ foals,

A.
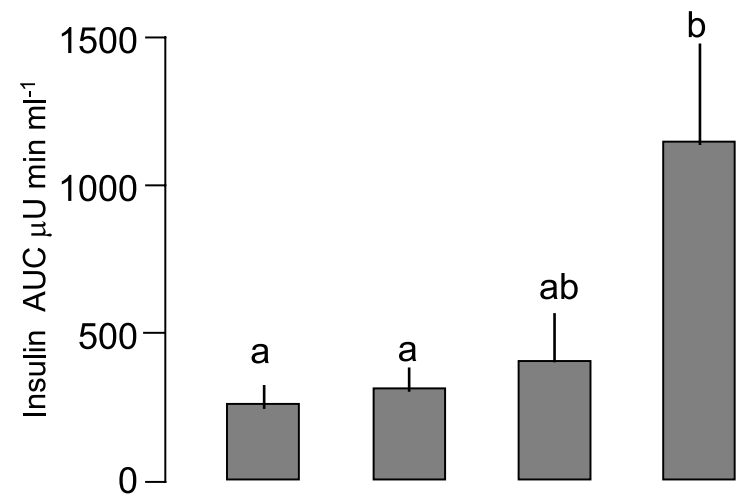

B.
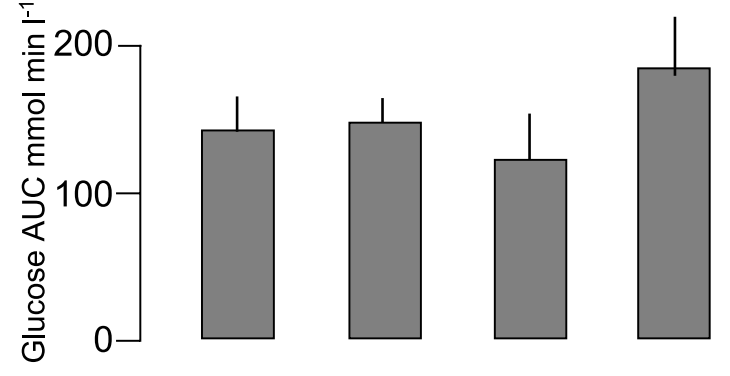

C.
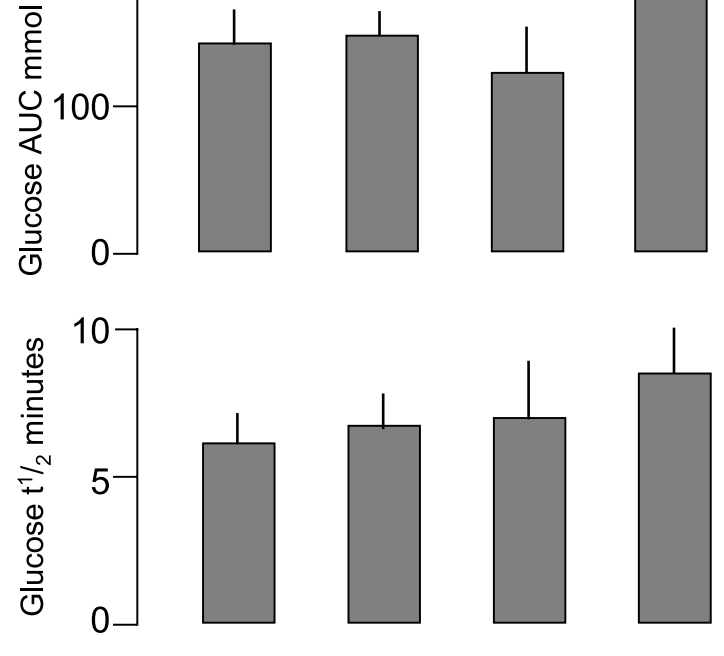

TB in TB TB in $P$

$\mathrm{P}$ in $\mathrm{P}$

$P$ in TB

Figure 2 Mean $( \pm$ S.E.) values of the area under the curve (AUC) of $(A)$ insulin concentration, $(B)$ glucose concentration and $(C)$ the half time $\left(t^{1} / 2\right)$ of glucose disappearance after glucose administration in the four groups of foals (TB in TB, $n=8$; TB in $P$, $n=8 ; P$ in $P, n=7 ; P$ in TB, $n=7)$. Bars with different superscripts are significantly different from each other $(P<0 \cdot 05$, one-way ANOVA). Two-way ANOVA of the data is presented only in the text.

irrespective of the maternal genome. However, there was a significant interaction between the fetal and maternal genomes in determining these variables, with larger insulin responses in $\mathrm{P}$ foals gestated in $\mathrm{TB}$ mares than in those carried by $\mathrm{P}$ mares $(P<0 \cdot 04)$. There were no significant differences in either the maximum increment in plasma glucose (Fig. 1A) or the glucose AUC (Fig. 2B) between the four groups of foals. Neither was there any significant difference in the half time for glucose disappearance between the groups (Fig. 2C).

The relationships between the plasma insulin and glucose concentrations in the four groups of foals are shown in Fig. 3. The slope of this relationship was greater in $\mathrm{P}$ than in TB foals irrespective of the maternal genome $(P<0 \cdot 05$ 


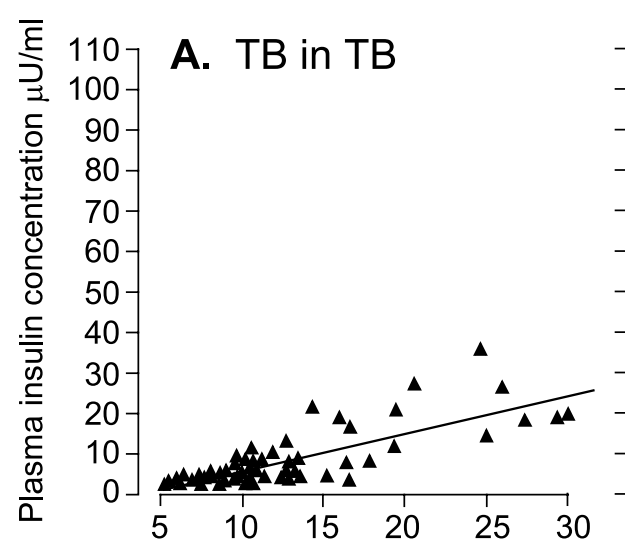

B. $T B$ in $P$

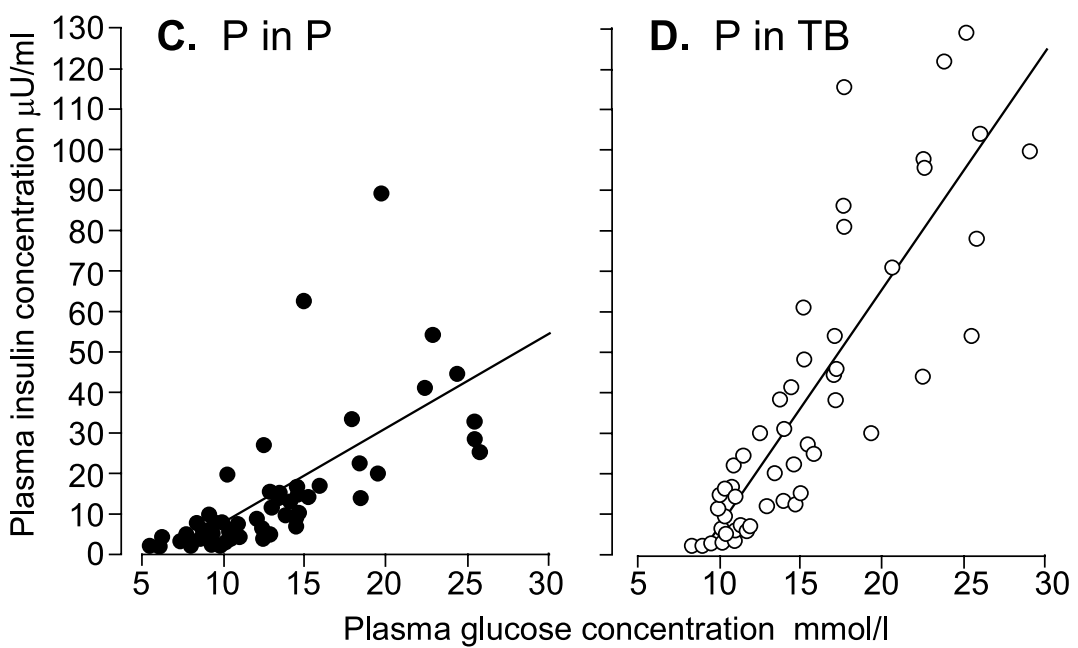

Figure 3 The relationship between the plasma concentrations of insulin and glucose before, and in response to, exogenous glucose administration in (A) eight TB foals in TB mothers $(\boldsymbol{\Delta} ; y=0.93 x-4 \cdot 4, n=72, r=0 \cdot 749, P<0.001)$, (B) eight TB foals in $\mathrm{P}$ mothers $(\triangle ; y=1 \cdot 08 x-5 \cdot 4, n=72, r=0 \cdot 807, P<0 \cdot 001),(C)$ seven $P$ foals in $P$ mothers (O) $y=2 \cdot 38 x-16 \cdot 3, n=63, r=0.632, P<0.001)$ and (D) seven $P$ foals in TB mothers $(\bigcirc ; y=5 \cdot 59 x-48 \cdot 75, n=63, r=0 \cdot 837, P<0 \cdot 001)$.

all cases) and was significantly steeper in the $\mathrm{P}$ in $\mathrm{TB}$ foals than in the other three groups of animals (Fig. 3, $P<0 \cdot 01$ all cases). No significant difference in the slope of the relationship between the plasma insulin and glucose concentrations was observed between the two groups of TB foals (Fig. 3A and B).

\section{Insulin sensitivity}

Administration of insulin caused a rapid fall in the plasma glucose concentration in all four groups of foals (Table 2). Plasma glucose levels were significantly lower than baseline values $5 \mathrm{~min}$ after insulin administration and were still falling $10 \mathrm{~min}$ later in all the groups of foals (Table 2). There were no significant differences in the absolute or percentage decrease in plasma glucose at $5 \mathrm{~min}$ after insulin administration between the four groups of foals
(Table 2). However, at $15 \mathrm{~min}$, the percentage fall in plasma glucose tended to be greater in TB than in $\mathrm{P}$ foals (Table 2, $P=0.09$ ). Two-way ANOVA of the data showed a significant effect of the fetal $(P<0 \cdot 012)$, but not the maternal $(P>0 \cdot 05)$, genome in determining the percentage decrease in plasma glucose 15 min after insulin administration, with a greater insulin sensitivity in TB than in $\mathrm{P}$ foals irrespective of the maternal genome. The basal concentration of plasma glucose was not significantly different between the four groups of foals (Table 2).

\section{Discussion}

These results demonstrate that variations in the intrauterine growth rate affect insulin secretion by the foal in the period immediately after birth. Fetal growth was 
manipulated by transferring embryos between small pony mares and larger Thoroughbred mares, and was related directly to the total area of placenta that developed within the differently sized uteri. However, in contrast to findings in other species (Holemans et al. 1997, Moss et al. 2001, Simmons et al. 2001, Poore \& Fowden 2002, Kind et al. 2003), it was only the overgrown P in TB foals, and not the growth retarded TB in $\mathrm{P}$ foals, that showed abnormalities in insulin secretion after birth. Similarly, it was the overgrown $\mathrm{P}$ in TB, not the growth retarded TB in P foals that had elevated blood pressure, enhanced adrenal adrenocorticotrophin sensitivity during hypotension and altered baroreflex function in the 6-7 days after birth (Giussani et al. 2003). These differences in postnatal function are unlikely to be due to the slight variations in gestational length between groups as the foals were all classified as mature at birth (Rossdale et al. 1984). Taken together, these findings indicate that, in the horse, enhancing fetal growth above the norm has a greater range of effects on postnatal cardiovascular and endocrine function than intrauterine growth retardation, at least in the immediate neonatal period.

The growth retarded TB in P foals had normal basal concentrations of plasma insulin and glucose and their $\beta$ cell responses to exogenous glucose were similar to those of the TB in TB control animals. There were also no significant differences in the half time for glucose disappearance, or in the sensitivity to exogenous insulin between the two groups of TB foals. In other species, impaired intrauterine growth is associated with changes in postnatal insulin secretion and/or insulin resistance of several tissues including the liver, fat and skeletal muscle (Holemans et al. 1997, Hoet \& Hanson 1999, Ozanne \& Hales 2002). The specific nature and extent of these changes depend on postnatal age and on the type and cause of the intrauterine growth retardation (Hales et al. 1996, Hoet \& Hanson 1999, Ozanne \& Hales 2002). In pigs and sheep growth retarded in utero, there is no evidence for glucose intolerance until after puberty (Moss et al. 2001, Poore \& Fowden 2002). In contrast, abnormalities in postnatal insulin secretion and resistance associated with low birth weight have been observed as early as 4 years of age in humans, and within the first week of life in rats following restriction of uterine blood flow during late gestation (Yajnik et al. 1995, Simmons et al. 2001). However, even in these species, the abnormalities become more pronounced with increasing postnatal age and only lead to overt diabetes in old age (Robinson et al. 1992, Phillips et al. 1994b, Petry et al. 2001, Simmons et al. 2001). Indeed, in rats deprived of protein in utero, and in the smaller of discordant twin lambs, glucose tolerance and insulin sensitivity can be enhanced during early postnatal life and only deteriorate after puberty (Langley-Evans et al. 1994, Clarke et al. 2000, Moss et al. 2001, Ozanne \& Hales 2002). In human populations, the greatest risk of glucose intolerance and Type 2 diabetes occurs in individuals who are born small and thin but who show rapid catch-up growth during late infancy and become obese as adults (Phillips et al. 1994a, Eriksson et al. 2003, Hales \& Ozanne 2003). The absence of any alteration in insulin secretion or sensitivity in the growth-retarded newborn TB in $\mathrm{P}$ foals suggests that it is the combination of pre- and postnatal environments, rather than intrauterine growth retardation per se, that conditions the association between low birth weight and subsequent abnormalities in glucose handling. Further studies of the $\mathrm{TB}$ in $\mathrm{P}$ foals later in life are required to establish whether retardation of fetal growth by embryo transfer may eventually lead to glucose intolerance in this species.

The overgrown $\mathrm{P}$ in TB foals had higher insulin levels and greater $\beta$ cell responses to exogenous glucose than the other groups of foals. The slope of the relationship between the plasma glucose and insulin concentrations was also significantly steeper in the $\mathrm{P}$ in $\mathrm{TB}$ foals than in the control $\mathrm{P}$ in $\mathrm{P}$ foals or in the two groups of TB foals. Glucosestimulated insulin secretion is, therefore, enhanced in the overgrown $\mathrm{P}$ in TB foals. These observations are consistent with previous findings of neonatal hyperinsulinaemia and hypersecretion of insulin in the macrosomic offspring of diabetic rats and women (Lindsey \& Bennett 2001, Aerts \& Van Assche 2003). The increased supply of nutrients provided by the larger placenta of the $\mathrm{P}$ in TB foals may have led to $\beta$ cell proliferation and/or changes in the mechanisms of insulin synthesis and secretion. Neogenesis of $\beta$ cells occurs throughout adult life in the horse (Helmstaedler et al. 1976), although relatively little is known about the intrauterine development of the endocrine pancreas in this species (Fowden et al. 1984). The pancreatic endocrine cells of the fetal horse are functional from mid gestation and are known to become progressively more responsive to stimuli during late gestation in normal pony pregnancies (Fowden et al. 1980, 1984, 1999). Certainly, the elevated insulin levels in the $P$ in TB foals may explain, in part, their larger size, since insulin is known to be an important growth factor in the fetus (Fowden 1995).

In humans and rats, fetal macrosomia induced by increasing the nutrient supply is often accompanied by increased fat deposition, a known risk factor for adult insulin resistance (Phillips et al. 1994a, Eriksson et al. 2003, Hales \& Ozanne 2003). Nothing is known about the body composition of the foals in the present study although the gross morphometry of the foals did differ between groups (Allen et al. 2002a,b). In humans, the expression of specific polymorphisms in the promotor region of the insulin gene is associated with enhanced birth weight, hyperinsulinaemia and an increased risk of adult glucose intolerance (Ong \& Dunger 2001). The enhanced insulin levels found in the $\mathrm{P}$ in TB foals could, therefore, reflect epigenetic programming of the regulatory regions of the insulin gene(s) during early development in the larger TB uterus. Alternatively, the hyperinsulinaemia may have a postnatal 
rather than a prenatal origin. Gastrointestinal peptides are known to enhance insulin secretion by the adult pancreas and their concentrations rise rapidly after feeding in the newborn foal (Ousey et al. 1995). Exposure to these peptides per kg bodyweight may have been greatest in the $\mathrm{P}$ in TB foals as these foals were small relative to the milk supply offered by the larger TB mammary gland.

Although the insulin response to glucose was enhanced in the $\mathrm{P}$ in TB foals, there was no significant difference in the half time for glucose disappearance between any of the groups of foals. This observation, coupled with the hyperinsulinaemia and elevated insulin to glucose concentration ratio in the $\mathrm{P}$ in $\mathrm{TB}$ foals, suggests that these animals were more resistant to the hypoglycaemic actions of insulin than the other groups of foals. Enhanced insulin secretion may, therefore, have been a compensatory mechanism to maintain glucose homeostasis in the relatively insulin resistant $\mathrm{P}$ in TB foals. However, insulin sensitivity, measured as glucose decrement to exogenously administered insulin, was not significantly different between the $\mathrm{P}$ in $\mathrm{TB}$ foals and their $\mathrm{P}$ in $\mathrm{P}$ controls. Further studies using more sensitive indices of insulin sensitivity, such as the hyperinsulinaemic euglycaemic clamp, would be needed to confirm if $\mathrm{P}$ in $\mathrm{TB}$ foals are more insulin resistant than $\mathrm{P}$ in $\mathrm{P}$ control animals.

The $\mathrm{P}$ foals had larger $\beta$ cell responses to glucose than the TB foals irrespective of maternal breed. In part, this may have been due to differences in the concentrations of other hormones involved in regulating insulin secretion (Fowden 1995, Giussani et al. 2003). However, there were no differences in the glucagon or adrenaline concentrations between groups in the current study, and the breed differences in plasma noradrenaline would have tended to suppress, not enhance glucose-stimulated insulin secretion in the $\mathrm{P}$ foals (Fowden 1995). Nor was there any indication from the PCV and haemoglobin concentrations at birth of breed differences in prenatal or intrapartum stress that may have accounted for the differences in neonatal $\beta$ cell function. Since glucose tolerance was similar in TB and P foals, it is more likely that the breed differences in neonatal insulin secretion were directly linked to the reduced insulin sensitivity observed in $\mathrm{P}$ compared with TB foals. In turn, this may have reflected the breed differences in plasma noradrenaline. Since adult insulin sensitivity is known to be lower in ponies than in more athletic breeds of horse (Jeffcott et al. 1986, Forhead \& Dobson 1997), genotype, rather than intrauterine conditions, may also be the major determinant of insulin sensitivity in the newborn foal.

In summary, this study, together with our previous observations (Allen et al. 2002a, Giussani et al. 2003), show that both enhancement and retardation of fetal growth in the horse leads to altered postnatal cardiovascular, endocrine and metabolic functions. The present findings demonstrate that alterations in fetal growth above but not below the normal trajectory for the breed leads to abnormalities in the secretion and effectiveness of insulin in the immediate neonatal period. Whether these abnormalities resolve, persist or magnify with increasing postnatal age remains unknown but they are likely to affect neonatal metabolism and growth, which, in turn, may programme glucose handling later in life (Hales \& Ozanne 2003). The horse is, therefore, a useful model in which to investigate the intrauterine origin of adult glucose intolerance.

\section{Acknowledgements}

The authors would like to thank Mr Eddie Sear and Ms Caroline Turnbull for their help with the experimental procedures, Mr Malcolm Bloomfield for his assistance with the biochemical analyses and Miss Nicola Allanson and Mrs Dee Hughes for their help with the preparation of the manuscript.

\section{Funding}

The project was funded by the Horserace Betting Levy Board and the Thoroughbred Breeders' Association.

\section{References}

Aerts L \& Van Assche FA 1979 Is gestational diabetes an acquired condition? Journal of Developmental Physiology 1 219-225.

Aerts L \& Van Assche FA 2003 Intra-uterine transmission of disease. Placenta 24 905-911.

Allen WR, Wilsher S, Turnbull C, Stewart F, Ousey J, Rossdale PD \& Fowden AL 2002a Influence of maternal size on placental, fetal and postnatal growth in the horse. I. Development in utero. Reproduction 123 445-453.

Allen WR, Wilsher S, Steward F, Ousey J \& Fowden A $2002 b$ The influence of maternal size on placental, fetal and postnatal growth in the horse. II. Endocrinology of pregnancy. Journal of Endocrinology 172 237-246.

Armitage P \& Berry G 1994 Further analyses of straight-line data. In Statistical Methods in Medical Research, pp 292-305. Oxford: Blackwells.

Clarke L, Firth K, Heasman L, Juniper DT, Budge H, Stephenson \& Symonds ME 2000 Influence of relative size at birth on growth and glucose homeostasis in twin lambs during juvenile life. Reproduction, Fertility and Development 12 69-73.

Eriksson JG, Forsén T, Tuomilehto J, Osmond C \& Barker DJP 2003 Early adiposity rebound in childhood and risk of Type 2 diabetes in adult life. Diabetologia 46 190-194.

Forhead AJ \& Dobson H 1997 Plasma glucose and cortisol responses to exogenous insulin in fasted donkeys. Research in Veterinary Science 62 265-269.

Fowden AL 1995 Endocrine regulation of fetal growth. Reproduction, Fertility and Development 7 351-363.

Fowden AL, Barnes RJ, Comline RS \& Silver M 1980 Pancreatic $\beta$ cell function in the fetal foal and mare. Journal of Endocrinology 87 293-301.

Fowden AL, Comline RS \& Silver M 1984 Insulin secretion and carbohydrate metabolism during pregnancy in the mare. Equine Veterinary Journal 16 239-246. 
Fowden AL, Forhead AJ, Bloomfield M, Taylor PM \& Silver M 1999 Pancreatic $\alpha$ cell function in the fetal foal during late gestation. Experimental Physiology 84 697-705.

Giussani DA, Forehead, AJ, Gardner DS, Fletcher AJW, Allen WR \& Fowden AL 2003 Postnatal cardiovascular function after manipulation of fetal growth by embryo transfer in the horse. Journal of Physiology 547 67-76.

Hales CN \& Barker DJP 1992 Type 2 (non-insulin-dependent) diabetes mellitus: the thrifty phenotype hypothesis. Diabetologia 35 595-601.

Hales CN \& Ozanne SE 2003 The dangerous road of catch-up growth. Journal of Physiology 547 5-10.

Hales CN, Barker DJ \& Clarke PM 1991 Fetal infant growth and impaired glucose at age 64. British Medical Journal 303 1019-1022.

Hales CN, Desai M, Ozanne SE \& Crowther NJ 1996 Fishing in the stream of diabetes: from measuring insulin to the control of fetal organogenesis. Biochemical Society Transactions 24 341-350.

Helmstaedler V, Feurle GE \& Forssmann WG 1976 Insulin-, glucagon-, and somatostatin-immunoreactive endocrine cells in the equine pancreas. Cell and Tissue Research 172 447-454.

Hoet JJ \& Hanson MA 1999 Intrauterine nutrition: its importance during critical periods for cardiovascular and endocrine development. Journal of Physiology 514 617-627.

Holemans K, van Bree, R, Verhaeghe J, Meurrens K \& van Assche FA 1997 Maternal semistarvation and streptozotocin-diabetes in rats have different effect on the in vivo glucose uptake by peripheral tissues in their female adult offspring. Journal of Nutrition 127 1371-1376.

Jeffcott L, Field JR, McLea JG \& O’Dea K 1986 Glucose tolerance and insulin sensitivity in ponies and standard bred horses. Equine Veterinary Journal 18 97-101.

Kind KL, Clifton PM, Grant PA, Owens PC, Sohlstrom A, Roberts CT, Robinson JS \& Owens JA 2003 Effect of maternal feed restriction during pregnancy on glucose tolerance in the adult guinea pig. American Journal of Physiology 284 R140-R152.

Langley-Evans SC, Browne RF \& Jackson AA 1994 Altered glucose tolerance in rats exposed to maternal low protein diets in utero. Comparative Biochemistry and Physiology 109 223-229.

Lindsay RS \& Bennett PH 2001 Type 2 diabetes, the thrifty phenotype - an overview. British Medical Bulletin 60 21-32.

Moss TJ, Slobade DM, Gurrin LC, Harding R, Challis JRG \& Newman JP 2001 Programming effect in sheep of prenatal growth restriction and glucocorticoid exposure. American Journal of Physiology 281 R960-R970.

Ong KL \& Dunger DB 2001 Developmental aspects in the pathogenesis of type 2 diabetes. Molecular and Cellular Endocrinology 185 145-149.

Ousey J, Ghatei M, Rossdale PD \& Bloom SR 1995 Gut hormone response to feeding in healthy pony foals aged 0 to 7 days. Biology of Reproduction Monograph Series 1 87-96.

Ozanne SE \& Hales CN 2002 Early programming of glucose-insulin metabolism. Trends in Endocrinology and Metabolism 13 368-373.

Petry CJ, Davline MW, Pawlak DB, Ozanne SE \& Hales CN 2001 Diabetes in old male offspring of rat dams fed a reduced protein diet. International Journal of Experimental Diabetes Research 2 139-143.
Phillips DIW, Barker DJP, Hales CN, Hirst S \& Osmond C 1994a Thinness at birth and insulin resistance in adult life. Diabetologia $\mathbf{3 7}$ 150-154.

Phillips DIW, Hirst S, Clark PMS, Hales CN \& Osmond C $1994 b$ Fetal growth and insulin secretion in adult life. Diabetologia $\mathbf{3 7}$ 592-596.

Plagemann A, Harder T, Kohlhoff R, Rohde W \& Dörner G 1997 Glucose tolerance and insulin secretion in children of mothers with pregestational IDDM or gestational diabetes. Diabetologia $\mathbf{4 0}$ 1094-1100.

Poore KR \& Fowden AL 2002 The effect of birth weight on glucose tolerance in pigs at 3 and 12 months of age. Diabetologia $\mathbf{4 5}$ $1247-1254$

Poulsen P, Vaag AA, Kyvik KO, Moller Jenson D \& Beck-Nielsen H 1997 Low birth weight is associated with NIDDM in discordant monozygotic and dizygotic twin pairs. Diabetologia 40 439-446.

Ravelli ACJ, van der Meulen JHP, Michels RPJ, Osmond C, Barker DJP, Hales CN \& Bleker OP 1998 Glucose tolerance in adults after prenatal exposure to famine. Lancet 351 173-177.

Robinson S, Walton RJ, Clark PM, Barker DJP, Hales CN \& Osmond C 1992 The relation of fetal growth to plasma glucose in young men. Diabetologia 35 444-446.

Rossdale PD 1976 A clinician's view of prematurity and dysmaturity in Thoroughbred foals. Journal of the Royal Society of Medicine 69 631-632.

Rossdale PD, Ousey JC, Silver M \& Fowden AL 1984 Studies on equine prematurity. 6. Guidelines for assessment of foal maturity. Equine Veterinary Journal 16 300-302

Silver M, Fowden AL, Ousey JC, Knox J, Franco R \& Rossdale PD 1987 Sympathoadrenal response to hypoglycaemia in the foal. Journal of Reproduction and Fertility (Suppl) 35 607-614.

Simmons RA, Templeton LJ \& Gertz SJ 2001 Intrauterine growth retardation leads to the development of type 2 diabetes in the rat. Diabetes 50 2279-2286.

Steven DH 1975 Anatomy of the placental barrier. In Comparative Placentation, pp 25-57. Ed. DH Steven. London: Academic Press.

Tischner M 1987 Development of Polish pony foals born after embryo transfer to large mares. Journal of Reproduction and Fertility (Suppl) 35 705-709.

Walton A \& Hammond J 1938 The maternal effects of growth and contamination in Shire horse-Shetland pony crosses. Proceedings of the Royal Society of London Series B 125 311-335.

Williams MA, Emanuel I, Kimpo C, Leisenring WM \& Hale CB 1999 A population-based cohort study of the relation between maternal birth weight and risk of gestational diabetes in four racial/ethnic groups. Pediatric and Perinatal Epidemiology 13 452-465.

Yajnik CS, Fall DHD, Vaidya U, Pandit AN, Bavdekar A, Bhat DS, Osmond C, Hales CN \& Barker DJP 1995 Fetal growth and glucose and insulin metabolism in four-year-old Indian children. Diabetic Medicine 12 330-336.

Received in final form 30 January 2004

Accepted 4 March 2004 